\title{
Solidification structure simulation and casting process optimization of GCr15 bloom alloy
}

\author{
Jie Li, Hao-tian Wu, Yang Liu, and *Yan-hui Sun \\ Collaborative Innovation Center of Steel Technology, University of Science and Technology Beijing, Beijing 100083, China
}

\begin{abstract}
Based on the solidification heat transfer model and CAFÉ model, the solidification structure of GCr15 bloom alloy was studied. Using nail shooting and acid etching experiments, the solidification models were verified. The secondary dendrite arm spacing (SDAS) model of GCr15 was obtained by simulation calculation and metallographic observation. With the increase of casting speed, the SDAS, equiaxed crystal ratio (ECR) and average grain size increase. With the rise of superheat, the SDAS increases in the 20-70 mm of thickness and decreases in the $80-160 \mathrm{~mm}$ of thickness. The ECR decreases and the average grain size increases with the increase of superheat. With the increase of specific water flow, both the SDAS and ECR decrease. The minimum average grain size is obtained when the specific water flow is $0.20 \mathrm{~L} \cdot \mathrm{kg}^{-1}$. The central carbon segregation index is reduced from 1.11 to 1.075 .
\end{abstract}

Keywords: numerical simulation; continuous casting; equiaxed crystal ratio; secondary dendrite arm spacing; carbon segregation
CLC numbers: TG142
Document code: A
Article ID: 1672-6421(2022 01-063-12

\section{Introduction}

Continuous casting process is the main method to prepare GCr15 steel, but the macrosegregation of bloom is very serious, which leads to inhomogeneity of the mechanical properties of final products ${ }^{[1]}$. Although prolonging the reheating time reduces the macrosegregation, it increases the production cost. The best opportunity to control macrosegregation is still in the casting process. There are two main means to control the macrosegregation of bloom, which are soft reduction and electromagnetic stirring ${ }^{[2-5]}$. The main purposes of these two means are to compensate the solidification end shrinkage and improve the equiaxed crystal rate (ECR). However, the influence of solidification characteristics structure on macrosegregation should not be ignored. Both primary dendritic arms spacing (PDAS) and secondary dendritic arm spacing (SDAS) are significant parameters that characterize the solidification structure ${ }^{[6]}$. El-Bealy et al. ${ }^{[7]}$ established mathematical models to predict SDAS, and found that SDAS has an exponential relationship with the local solidification time (LST). An et al. ${ }^{[8]}$ found smaller SDAS can make the

\section{*Yan-hui Sun}

Male, born in 1971, Ph. D, Professor. His research interests mainly focus on the bloom quality control and inclusion control.

E-mail: sunyanhui@metall.ustb.edu.cn

Received: 2021-04-28; Accepted: 2021-12-11 solidification structure more compact, which reduced the frequency of central segregation. To obtain a small SDAS, a high cooling intensity is required, and a high cooling intensity reduces the ECR. In contrast, a high ECR is generally considered to be conducive to reducing macrosegregation. Therefore, the effect of solidification structure on macrosegregation needs to be further studied.

In the present study, to eliminate the macrosegregation, GCr15 steel blooms with a section of $320 \mathrm{~mm} \times 480 \mathrm{~mm}$ were prepared by continuous casting. A solidification heat transfer model and CAFÉ model of the steel blooms were established based on the ProCAST software, and verified by nail shooting and acid etching experiments. Based on experiment and numerical simulations, a new SDAS model for GCr15 bloom was developed. The effects of continuous casting process parameters, such as casting speed, superheat and cooling intensity, on ECR, SDAS and average grain size of the steel were investigated. An optimization scheme was proposed to improve center segregation.

\section{Main technological parameters of continuous casting and methods}

The GCr15 blooms were produced by an arc continuous caster. The main technological parameters of the continuous caster are shown in Table 1. The main chemical compositions of GCr15 steel are listed in Table 2.

To study the effect of continuous casting process 
Table 1: Main technological parameters of the continuous caster

$\begin{array}{cc}\text { Parameters } & \text { Value } \\ \text { Caster radius }(\mathrm{m}) & 10.5 \\ \text { Sectional dimension }\left(\mathrm{mm}^{2}\right) & 480 \times 320 \\ \text { Effective length of mold }(\mathrm{m}) & 0.70 \\ \text { Length of secondary cooling zone }(\mathrm{m}) & 6.87 \\ \text { Length of air-cooling zone }(\mathrm{m}) & 17.68 \\ \text { Casting speed }\left(\mathrm{m} \cdot \mathrm{min}^{-1}\right) & 0.40-0.70\end{array}$

Table 2: Main chemical compositions of GCr15 steel (mass\%)

$\begin{array}{ccccccc}\mathbf{C} & \text { Si } & \text { Mn } & \mathbf{P} & \mathbf{S} & \mathbf{C r} & \mathrm{Fe} \\ 0.967 & 0.229 & 0.314 & 0.006 & 0.001 & 1.470 & \text { Bal. }\end{array}$

parameters on solidification structure, solidification heat transfer model and CAFÉ model were established. To verify the accuracy of the model, nail shooting test and slab pickling test were carried out. The nail shooting sample of $480 \mathrm{~mm} \times 320 \mathrm{~mm} \times 30 \mathrm{~mm}$ was cut from the bloom, and the surface with the nail mark was polished and etched with aqueous hydrochloric acid to measure the shell thickness. A 90-100 mm long bloom obtained was cut off by flame cutting. The heat affected zone was removed by using the sawing machine, and a $15 \mathrm{~mm}$ thick sample for pickling test with the sectional dimension of $480 \mathrm{~mm} \times 320 \mathrm{~mm}$ was obtained. The sample was finished by milling machine and ground. Then, the sample for solidification structure observation was obtained after acid etching for $20 \mathrm{~min}$ in aqueous hydrochloric acid solution at about $343 \mathrm{~K}$.

To evaluate the effects of casting speed, superheat and specific water content on the bloom solidification structure, the solidification structures of the bloom with a casting speed of $0.45-0.54 \mathrm{~m} \cdot \mathrm{min}^{-1}$, superheat $10-40 \mathrm{~K}$ and specific water content $0.13-0.23 \mathrm{~L} \cdot \mathrm{kg}^{-1}$ were simulated with the heat transfer model and CAFÉ model.

Drilling cuttings were performed from the bloom samples before and after process optimization, and the carbon contents were analyzed by carbon sulfur analyzer.

\section{Model description}

\subsection{Solidification heat transfer model}

\subsubsection{Governing equations and thermophysical parameters}

To simplify the calculation of the model, the following assumptions are made: the heat transfer in the casting direction is ignored; the cooling intensity of the same cooling section is uniform, and the inner and outer arcs are symmetric.

According to Fourier's law and the relationship between enthalpy and specific heat, the governing equations for the simplified heat transfer calculation of the solidification process are as follows:

$$
\begin{gathered}
\frac{\partial(\rho H)}{\partial t}=\frac{\partial}{\partial x}\left(k \frac{\partial T}{\partial x}\right)+\frac{\partial}{\partial y}\left(k \frac{\partial T}{\partial y}\right) \\
H=\int_{0}^{T} c \mathrm{~d} T+\left(1-f_{s}\right) L
\end{gathered}
$$

where $H$ is the enthalpy, $\mathrm{J}_{\mathrm{kg}}{ }^{-1} ; \rho$ is the density of steel, $\mathrm{kg} \cdot \mathrm{m}^{-3}$; $t$ is solidification time, $\mathrm{s} ; T$ is temperature, $\mathrm{K} ; k$ is the thermal conductivity, $\mathrm{W} \cdot \mathrm{m}^{-1} \cdot \mathrm{K}^{-1} ; x$ and $y$ are the coordinates, $\mathrm{m} ; c$ is the specific heat, $\mathrm{J} \cdot \mathrm{kg}^{-1} \cdot \mathrm{K}^{-1} ; f_{\mathrm{s}}$ is the solid fraction; and $L$ is the solidification latent heat, $\mathrm{J}_{\mathrm{kg}^{-1}}$.

The thermal conductivity, density, enthalpy and solid fraction can be obtained from the database of ProCAST software according to the steel compositions. The calculated results are shown in Fig. 1. The liquidus and solidus temperatures are 1,731 and $1,610 \mathrm{~K}$, respectively.

\subsubsection{Geometric model and calculation method of boundary conditions}

Thin-slicing method was used to simulate the solidification process of GCr15 steel bloom. To reduce the amount of calculation, a quarter of the bloom section was used in the model for calculation. The size of the slice is $240 \mathrm{~mm} \times 160 \mathrm{~mm} \times 10 \mathrm{~mm}$. Figure 2 shows the information about the geometric model and mesh generation.

In the whole solidification process, the bloom passes through the mold, the secondary cooling zone and the air-cooling zone in sequence.

(1) Boundary conditions of mold

In the mold, the heat flux was calculated by Eq. (3) ${ }^{[9]}$ :

$$
\begin{gathered}
q_{\mathrm{m}}=(2.688-\beta \sqrt{t}) \times 10^{3} \\
\beta=\frac{1.5 \times\left(2.688 \times 10^{3}-q_{\mathrm{e}}\right)}{\sqrt{l_{\mathrm{m}} / v}}
\end{gathered}
$$

where $q_{\mathrm{m}}$ is the heat flux of mold, $\mathrm{kW} \cdot \mathrm{m}^{-2} ; \beta$ is a coefficient depending on the mold cooling condition, $\mathrm{kW} \cdot \mathrm{m}^{-2} \cdot \min ^{-1 / 2} ; q_{\mathrm{e}}$ is the average heat flux in the mold, $\mathrm{kW} \cdot \mathrm{m}^{-1} ; l_{\mathrm{m}}$ is the effective length of the mold, $\mathrm{m}$; $t$ is the time in the mold, $\mathrm{s} ; v$ is the casting speed, $\mathrm{m} \cdot \mathrm{s}^{-1}$.

(2) Boundary conditions of secondary cooling zone

In the secondary cooling zone, there are three different ways of heat transfer in the five sub-zones for the bloom on the two wide faces, as shown in Fig. 3. The heat flux of the secondary cooling zone $\left(q_{\mathrm{s}}\right)$ can be expressed by:

$$
q_{\mathrm{s}}=q_{\mathrm{c}}+q_{\mathrm{rad}}+q_{\mathrm{w}}
$$

where $q_{\mathrm{c}}$ is the heat flux by contacting with the rolls, $q_{\mathrm{rad}}$ is the radiation flux, and $q_{\mathrm{w}}$ is the heat flux by spray cooling, $\mathrm{kW} \cdot \mathrm{m}^{-2}$.

For the two narrow faces of the bloom in the cooling zone, there are two different ways of heat transfer, which are radiation and spray cooling, respectively. The heat flux of the 
(a)

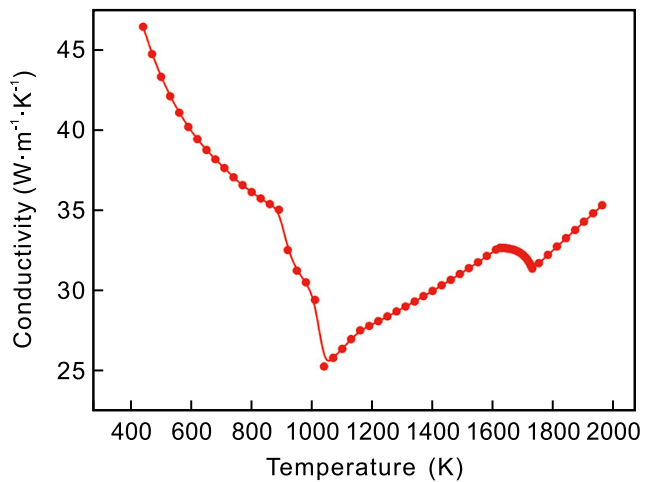

(c)

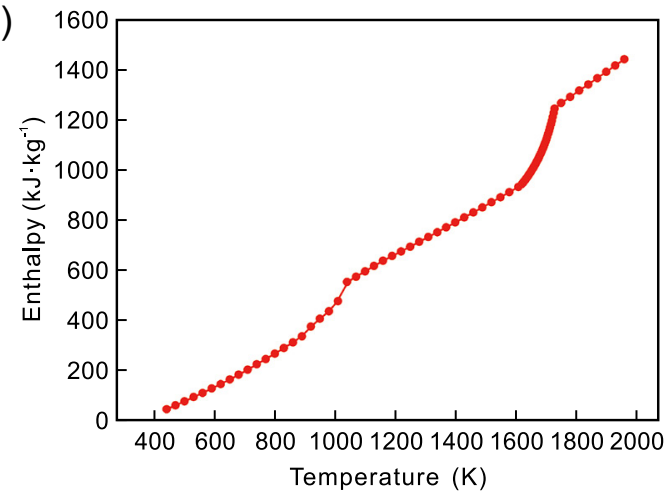

(b)

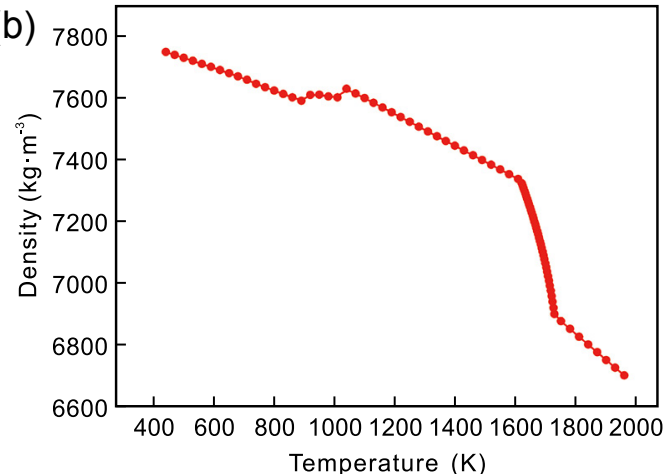

(d)

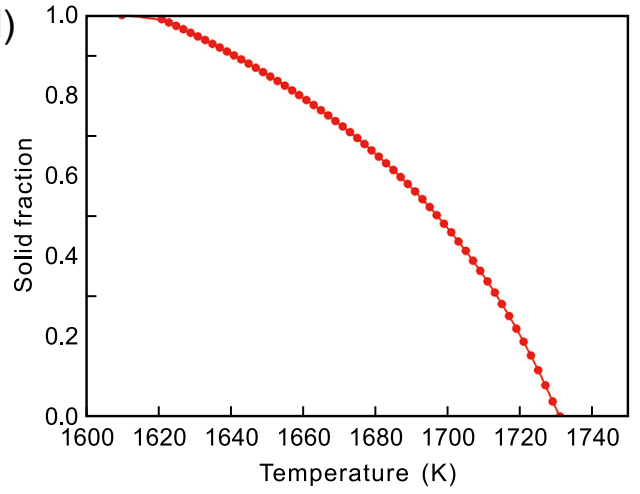

Fig. 1: Thermophysical parameters of GCr15: (a) thermal conductivity; (b) density; (c) enthalpy; (d) solid fraction

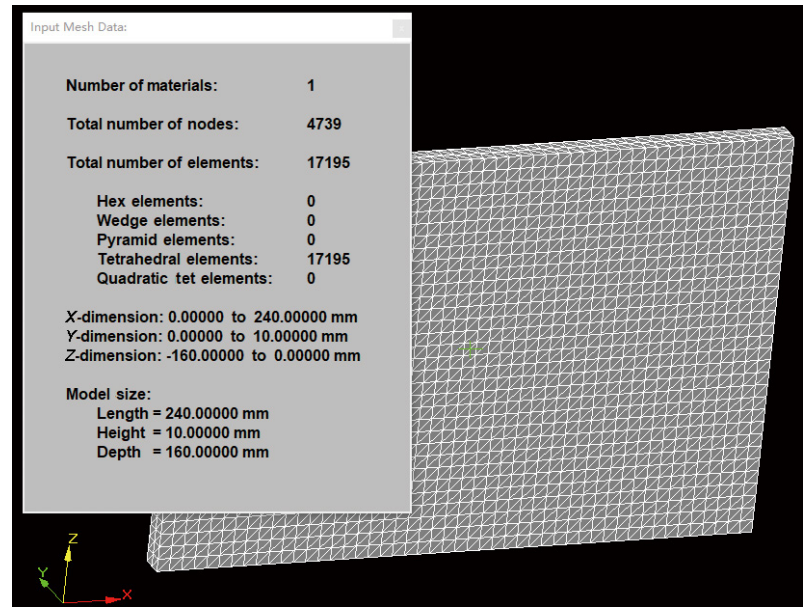

Fig. 2: Information about geometric model

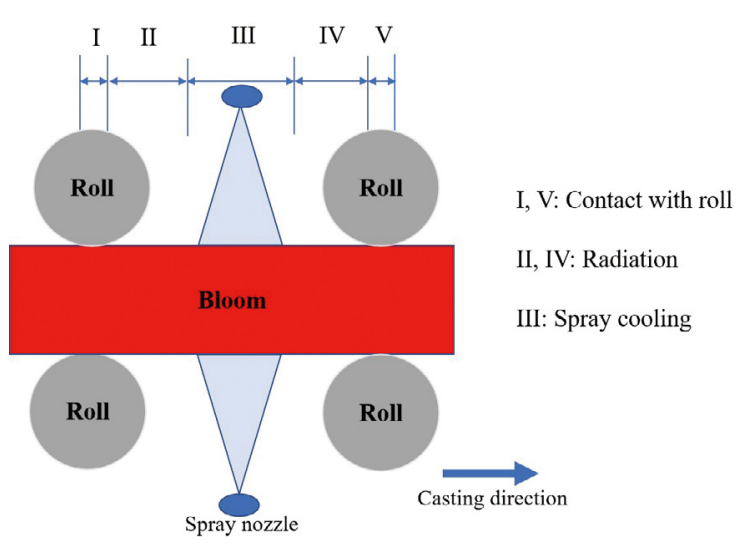

Fig. 3: Diagram of cooling mode in the secondary cooling zone secondary cooling zone can be expressed as:

$$
q_{\mathrm{s}}=q_{\mathrm{rad}}+q_{\mathrm{w}}
$$

In the Sub-zones I and V, the heat flux can be calculated by:

$$
q_{\mathrm{c}}=N h_{\mathrm{c}} \frac{L_{0}}{L}\left(T_{\mathrm{s}}-T_{\mathrm{r}}\right)
$$

where $N$ is the number of the rollers; $h_{\mathrm{c}}$ is the heat transfer coefficient between the surface of bloom and rolls, $\mathrm{kW} \cdot\left(\mathrm{m}^{2} \cdot \mathrm{K}\right)^{-1}$; $L_{0}$ is the contact length, $\mathrm{m} ; L$ is the length of the cooling zone, $\mathrm{m}$; $T_{\mathrm{s}}$ is the surface temperature of the bloom, $\mathrm{K} ; T_{\mathrm{r}}$ is the roll temperature, K. In this study, $L_{0}=5 \mathrm{~mm}, h_{\mathrm{c}}=2.5 \mathrm{~kW} \cdot\left(\mathrm{m}^{2} \cdot \mathrm{K}\right)^{-1}$, according to the previous research ${ }^{[10]}$.

In the Sub-zones II and IV, the heat flux can be calculated by:

$$
q_{\mathrm{rad}}=\varepsilon \sigma\left(T_{\mathrm{s}}^{4}-T_{\mathrm{amb}}^{4}\right)
$$

where $\sigma$ is the Stefan-Boltzmann constant, $5.67 \times 10^{-8} \mathrm{~W} \cdot\left(\mathrm{m}^{2} \cdot \mathrm{K}^{4}\right)^{-1}$; $\varepsilon$ is steel emissivity; $T_{\text {amb }}$ is the ambient temperature, $\mathrm{K}$.

The surface emissivity of steel can be calculated by the following equation ${ }^{[11]}$ :

$$
\varepsilon=\frac{0.85}{1+\exp \left(42.68-0.02682 T_{\mathrm{s}}\right)^{0.0115}}
$$

In the Sub-zone III, the heat flux can be calculated by:

$$
q_{\mathrm{w}}=h_{\mathrm{w}}\left(T_{\mathrm{s}}-T_{\mathrm{w}}\right)
$$

where $h_{\mathrm{w}}$ is the heat transfer coefficient of spray cooling, 
$\mathrm{kW} \cdot\left(\mathrm{m}^{2} \cdot \mathrm{K}\right)^{-1}$, which can be calculated by Eq. $(11)^{[12]}$.

$$
h_{\mathrm{w}}=1570 w^{0.55}\left(1-0.0075 T_{\mathrm{w}}\right) / \alpha
$$

where $w$ is the spray cooling flux, $\mathrm{L} \cdot\left(\mathrm{m}^{2} \cdot \mathrm{s}\right)^{-1} ; T_{\mathrm{w}}$ is the temperature of the spray cooling water, $\mathrm{K} ; \alpha$ is the machinedependent calibration factor.

(3) Boundary conditions of air-cooling zone

In the air-cooling zone, the heat flux can be calculated by Eqs. (8) and (9).

\subsubsection{Initial condition}

The initial condition is given by Eq. (12):

$$
T_{\text {ini }}=T_{\text {cast }}
$$

where $T_{\text {ini }}$ is the initial temperature of liquid steel, $\mathrm{K} ; T_{\text {cast }}$ is the steel temperature in the tundish, $\mathrm{K}$.

\subsection{CAFÉ model}

\subsubsection{Nucleation model}

The continuous nucleation model based on Gaussian distribution proposed by Rappaz ${ }^{[13,14]}$ was used, as shown in Eq. (13):

$$
\frac{\mathrm{d} n}{\mathrm{~d}(\Delta T)}=\frac{n_{\max }}{\sqrt{2 \pi} \cdot \Delta T_{\sigma}} \exp \left[-\frac{1}{2}\left\{\frac{\Delta T-\Delta \bar{T}}{\Delta T_{\sigma}}\right\}^{2}\right]
$$

where $n_{\max }$ is the maximum nucleation density, $\mathrm{m}^{-3}$ for volume and $\mathrm{m}^{-2}$ for surface; $\Delta T$ is the undercooling degree, $\mathrm{K} ; \Delta T_{\sigma}$ is the standard deviation undercooling, $\mathrm{K} ; \Delta \bar{T}$ is the mean ndercooling, $\mathrm{K}$.

\begin{tabular}{|c|c|c|c|c|c|c|}
\hline \multirow{2}{*}{ Parameters } & \multicolumn{3}{|c|}{ Surface nucleation } & \multicolumn{3}{|c|}{ Volume nucleation } \\
\hline & $\Delta T$ & $\Delta T_{\sigma}$ & $n_{\max }\left(m^{-2}\right)$ & $\Delta T$ & $\Delta T_{\sigma}$ & $n_{\max }\left(m^{-3}\right)$ \\
\hline Values & 1 & 0.1 & $5 \times 10^{7}$ & 3.3 & 0.1 & $1 \times 10^{8}$ \\
\hline
\end{tabular}
The nucleation parameters used in this study are listed in Table 3.

Table 3: Nucleation parameters used in calculation

\subsubsection{Dendrite tip growth model}

The KGT model ${ }^{[15]}$ was used to calculate the dendritic tip growth speed. According to the marginal stability criterion, the following equation can be obtained:

$$
V^{2} \frac{\pi^{2} \Gamma}{P^{2} D^{2}}+V \frac{m C_{0}\left(1-k_{0}\right)}{D\left[1-\left(1-k_{0}\right) I v(P)\right]}+G=0
$$

where $V$ is the growth velocity of the dendritic tip, $\mathrm{m} \cdot \mathrm{s}^{-1} ; \Gamma$ is the Gibbs-Thompson coefficient, $\mathrm{m} \cdot \mathrm{K} ; P$ is the Peclet number for solute diffusion; $D$ is the diffusion coefficients of solute elements in liquid, $\mathrm{m}^{2} \cdot \mathrm{s}^{-1} ; m$ is the slope of liquidus, $\mathrm{K} \cdot(\mathrm{wt} . \%)^{-1}$; $C_{0}$ is the initial concentration of solute elements, wt.\%; $k_{0}$ is the partition coefficient; $I v(P)$ is the Ivantsov function and $G$ is the temperature gradient, $\mathrm{K} \cdot \mathrm{m}^{-1}$. Since the temperature gradient has little effect on the growth velocity of the dendrite tip, the value of $G$ is set to zero.

The formula for calculating the undercooling degree of the dendrite tip is shown in Eq. (15):

$$
\Delta T=m C_{0}\left[1-\frac{1}{1-\left(1-k_{0}\right) I v(P)}\right]+\frac{2 \Gamma}{r}
$$

where $r$ is the dendritic tip radius, $\mathrm{m}$. The relationship between the growth velocity of the dendrite tip and the undercooling degree is shown in Eq. (16).

$$
V=a_{2} \Delta T^{2}+a_{3} \Delta T^{3}
$$

where $a_{2}$ and $a_{3}$ are the fitting coefficients, $\mathrm{m} \cdot \mathrm{s}^{-1} \cdot \mathrm{K}^{-2}$ and $\mathrm{m} \cdot \mathrm{s}^{-1} \cdot \mathrm{K}^{-3}$, which are calculated based on the data of partition coefficient, liquidus slope, diffusivity and Gibbs-Thompson coefficient of GCr15 steel. All these data are listed in Table 4.

\section{Results and discussion}

\subsection{Model validation}

\subsubsection{Validation of solidification heat transfer model}

The casting speed, superheat and specific water flow are $0.54 \mathrm{~m} \cdot \mathrm{min}^{-1}, 18 \mathrm{~K}$ and $0.16 \mathrm{~L} \cdot \mathrm{kg}^{-1}$, respectively. According to the above process parameters, the cooling parameters listed in Table 5 can be calculated.

The schematic diagram of the sampling process for the nail shooting sample is shown in Fig. 4(a). Figure 5(a) shows the photo of the bloom sample after acid etching. According to the position whether there is obvious diffusion around the nail, the shell thickness in the nail shooting experiment can be determined. The area with obvious diffusion is the mushy zone, and the area where the nail completely dissolves is the liquid zone. The measured and simulated shell thicknesses are $122 \mathrm{~mm}$ and $121 \mathrm{~mm}$, respectively, as shown in Fig. 5(b). It can be seen that the measured value is consistent with the calculated value, indicating the solidification heat transfer model can predict the solidification process very well.

Table 4: Parameters for dendrite tip growth kinetics

\begin{tabular}{ccccccc} 
Composition & C & Si & Mn & P & S & Cr \\
\hline $\begin{array}{c}\text { Liquidus slope, } m^{[16]} \\
\text { Partition coefficient, } k_{0}{ }^{[17]}\end{array}$ & -70 & -8 & -5.0 & -30 & -25 & -1.5 \\
$\quad 0.35$ & 0.54 & 0.78 & 0.08 & 0.05 & 0.85 \\
$\begin{array}{c}\text { Diffusivity in liquid, } D, \\
\quad \times 10^{-9} \mathrm{~m}^{2} \cdot \mathrm{s}^{-1}[18]\end{array}$ & 11.00 & 1.42 & 2.40 & 1.90 & 3.90 & 0.40 \\
$\begin{array}{c}\text { Gibbs-Thompson coefficient, } \Gamma, \\
\quad \times 10^{-7} \mathrm{~m}^{[19]}\end{array}$ & 3 & 3 & 3 & 3 & 3 & 3
\end{tabular}


Table 5: Cooling parameters used in simulation for verification of model

\begin{tabular}{|c|c|c|c|c|c|}
\hline \multirow{2}{*}{ Parameter } & \multirow{2}{*}{ Mold } & \multicolumn{4}{|c|}{ Secondary cooling zone } \\
\hline & & I & II & III & IV \\
\hline Length $(\mathrm{m})$ & 0.70 & 0.53 & 1.52 & 2.65 & 2.17 \\
\hline Cooling time (s) & 77.78 & 58.89 & 168.89 & 294.44 & 241.11 \\
\hline Boundary conditions of wide face & $\beta=280$ & $h_{\mathrm{w}}=191$ & $h_{\mathrm{w}}=110$ & $h_{\mathrm{w}}=70$ & $h_{\mathrm{w}}=85$ \\
\hline Boundary conditions of narrow face & $\beta=280$ & $h_{\mathrm{w}}=193$ & $h_{\mathrm{w}}=108$ & $h_{\mathrm{w}}=70$ & $h_{\mathrm{w}}=80$ \\
\hline
\end{tabular}
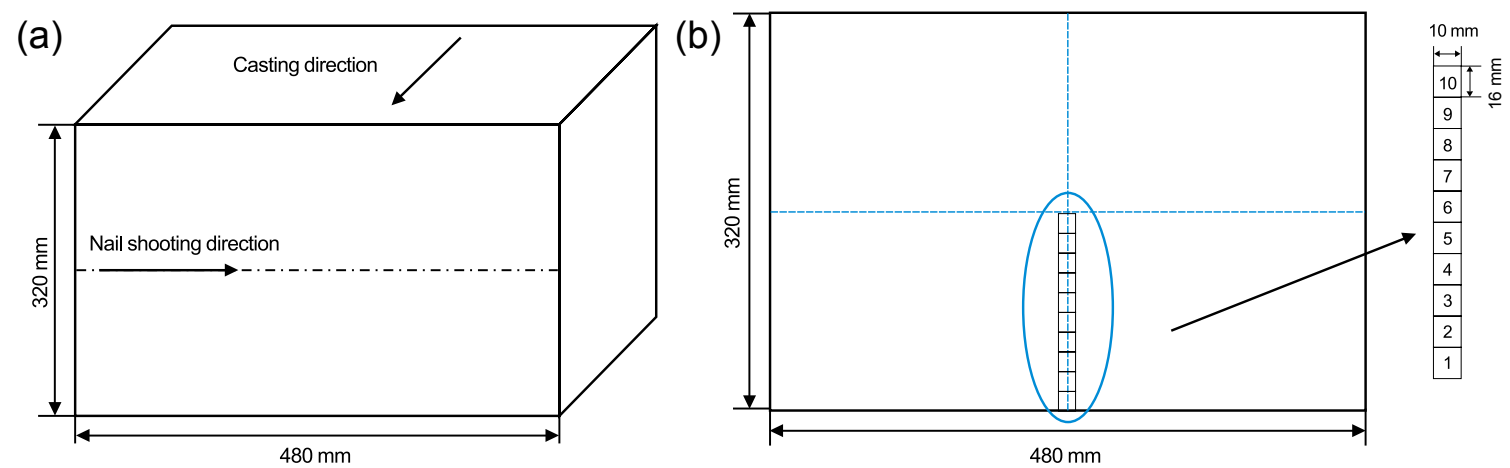

Fig. 4: Schematic diagram: (a) nail shooting; (b) samples for SDAS
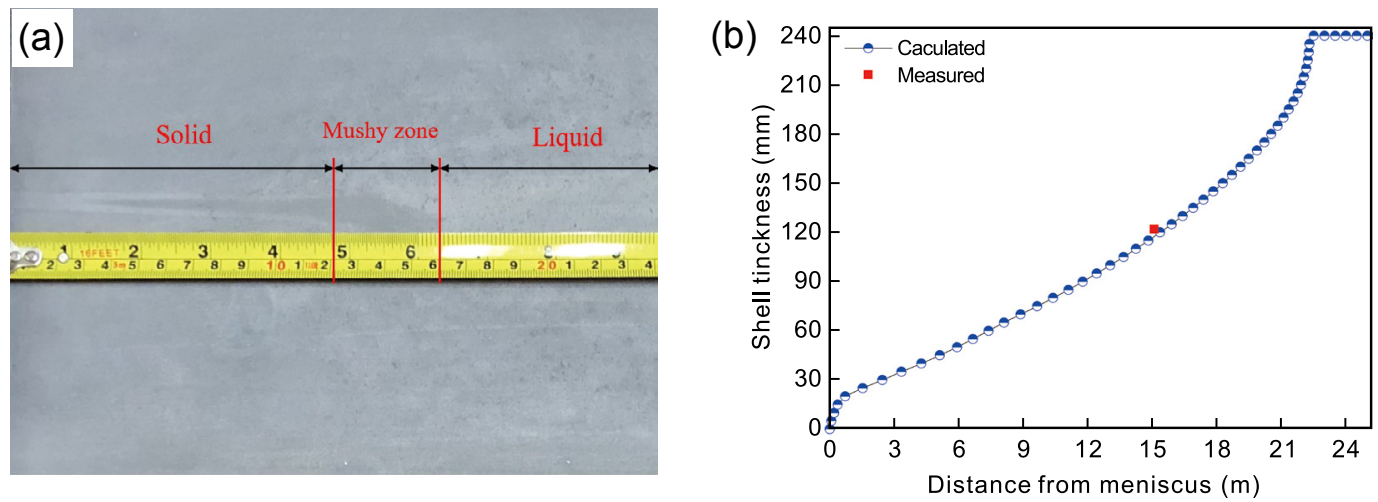

Fig. 5: Nail shooting experiment: (a) bloom sample for nail shooting experiment; (b) measured value and calculated curve of shell thickness

\subsubsection{Validation of CAFÉ model}

The CAFÉ model was validated by comparing the experimental and simulated solidification structures under the casting speed of $0.54 \mathrm{~m} \cdot \mathrm{min}^{-1}$, superheat of $20 \mathrm{~K}$ and specific water flow of $0.16 \mathrm{~L} \cdot \mathrm{kg}^{-1}$.

The macrograph of the solidification structure after pickling is shown in Fig. 6(a), and the ECR is $22.9 \%$. The ECR in the simulated solidification structure is $22.8 \%$, as shown in Fig. 6(b). The experimental and simulated ECR differs by less than $0.5 \%$, indicating the solidification structure can be well predicted by this model.

\subsection{SDAS model for $\mathrm{GCr} 15$}

Ten samples were taken from the surface to the center of the bloom, as shown in Fig. 4(b). The samples were etched with saturated picric acid and observed under a metallographic microscope. Under the condition of 40 times magnification, the average SDAS of each sample was measured. Micrographs of four samples are shown in Fig. 7.

Pequet et al. ${ }^{[20]}$ established a SDAS model at the mushy zone, as follows:

$$
\begin{gathered}
\lambda_{2}=\left[M(t) t_{\mathrm{L}}\right]^{1 / 3} \\
M(t)=\frac{\sigma_{\mathrm{sl}} D_{\mathrm{L}} T_{\mathrm{M}}}{L(1-k) m} \frac{\ln c_{1}(t)-\ln c_{1,0}}{c_{1}(t)-c_{1,0}}
\end{gathered}
$$

where $\lambda_{2}$ is the SDAS, $M(t)$ is the SDAS factor which mainly depends upon the properties of the alloy elements, $t_{\mathrm{L}}$ is the local solidification time (LST), $\sigma_{\mathrm{sl}}$ is the solid-liquid interfacial energy, $D_{\mathrm{L}}$ is the diffusion coefficient of solute in the liquid, $T_{\mathrm{M}}$ is the melting point of the pure system, $L$ the volumetric latent heat of fusion, $k$ is the equilibrium distribution coefficient, 

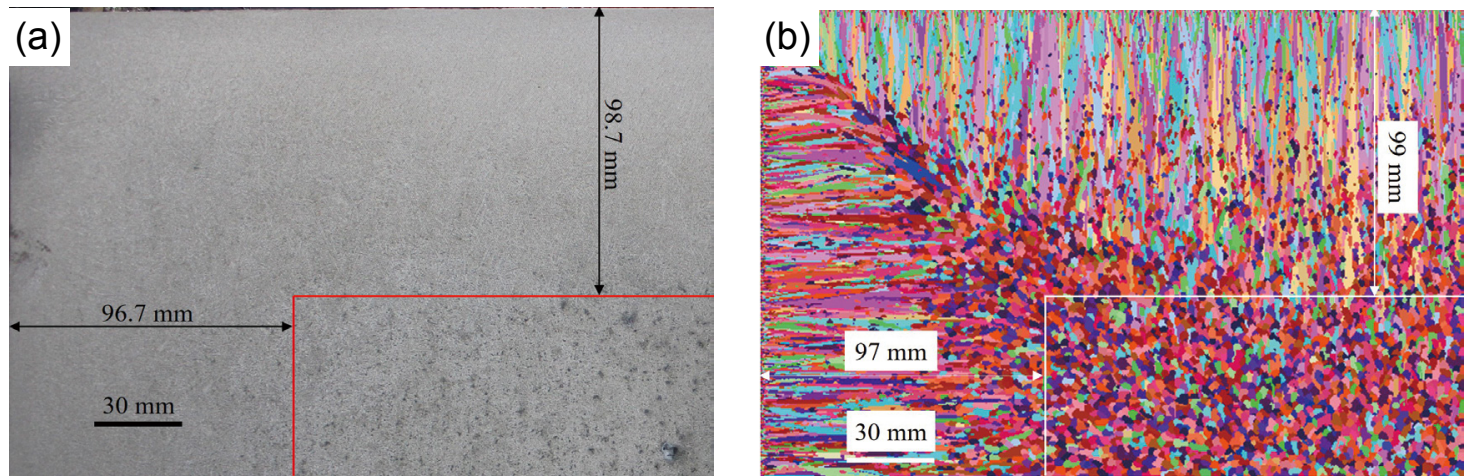

Fig. 6: Comparison between experimental (a) and simulated (b) solidification structure
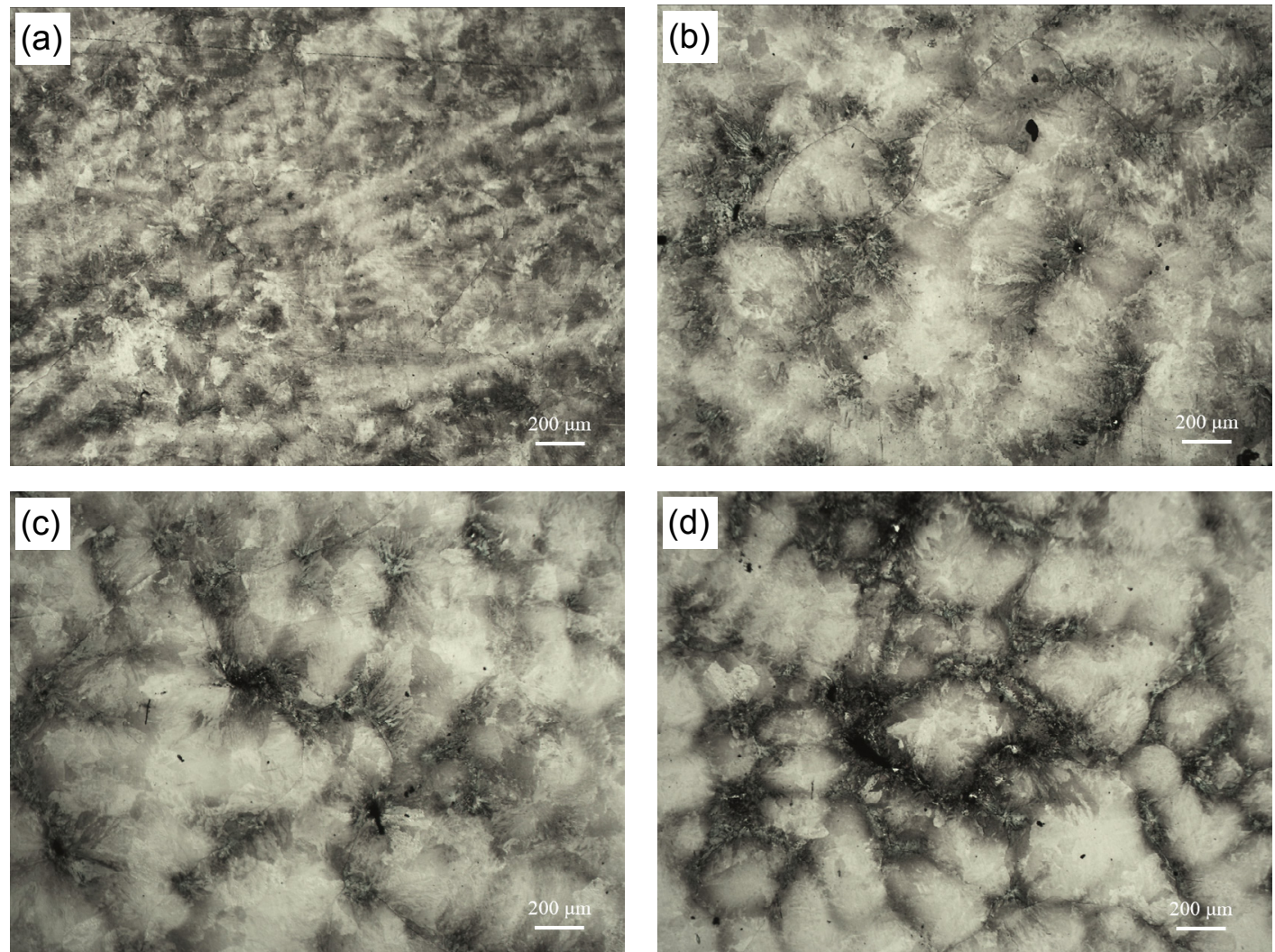

Fig. 7: Dendritic morphologies of four samples: (a) \#2; (b) \#5; (c) \#7; (d) \#9

$m$ is the liquidus slope of alloy elements, and $c_{1}(t)$ and $c_{1,0}$ are the current and nominal concentration of solute in the liquid, respectively.

According to Eq. (17), a simple model was developed to calculate the SDAS of GCr15 steel in this study as follows:

$$
\lambda_{2}=A t_{\mathrm{L}}^{1 / 3}
$$

Figure 8 shows the SDAS comparison between the calculated values with Eq. (19) and the measured ones. It can be found that the measured values are not much different from the calculated values. From the surface of the bloom to the center, the SDAS increases at first, and then slightly decreases, finally reaching a stable value. According to the measured SDAS and the calculated LST, $A=16.75$ can be obtained.

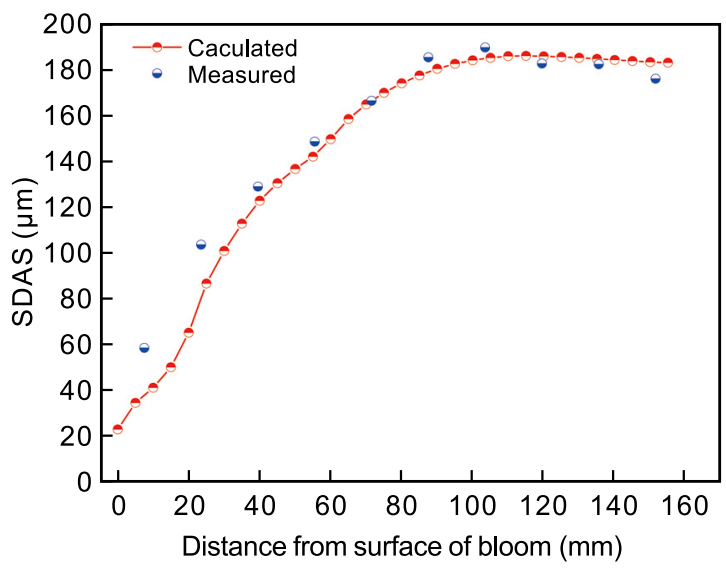

Fig. 8: Comparison between calculated and measured SDAS 


\subsection{Effect of process parameters on SDAS, $E C R$ and average grain size}

\subsubsection{Effect of casting speed}

With the superheat of $20 \mathrm{~K}$ and the specific water flow of $0.16 \mathrm{~L} \cdot \mathrm{kg}^{-1}$, the solidification process and solidification structure of the steel with various casting speeds of $0.45,0.48$, 0.51 and $0.54 \mathrm{~m} \cdot \mathrm{min}^{-1}$ were simulated.

The curves of SDAS versus shell thickness under different casting speeds are shown in Fig. 9. From the surface to the shell thickness of $60 \mathrm{~mm}$ of the bloom, the SDAS increases

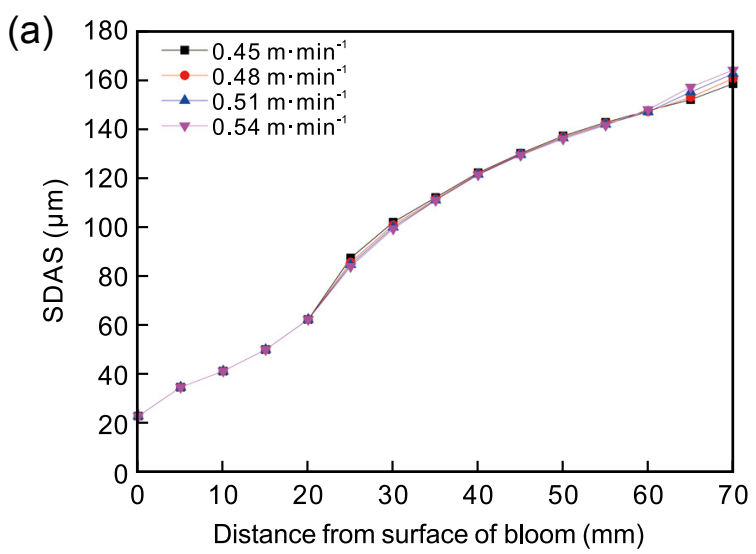

rapidly with the rise of the shell thickness [Fig. 9(a)]. The influence of casting speed on the SDAS is very small, which is mainly due to the similar cooling intensity in this region. When the distance from the surface of the bloom increases to 70-160 mm [Fig. 9(b)], the SDAS becomes stable and reaches the maximum value near $110 \mathrm{~mm}$, then decreases slowly. In this region, the SDAS increases with the increase of casting speed. The reason is that the increase of casting speed reduces the cooling rate and increases the LST. When the casting speed increases from 0.45 to $0.54 \mathrm{~m} \cdot \mathrm{min}^{-1}$, the SDAS increases about $2 \mu \mathrm{m}$ at the center of the bloom.

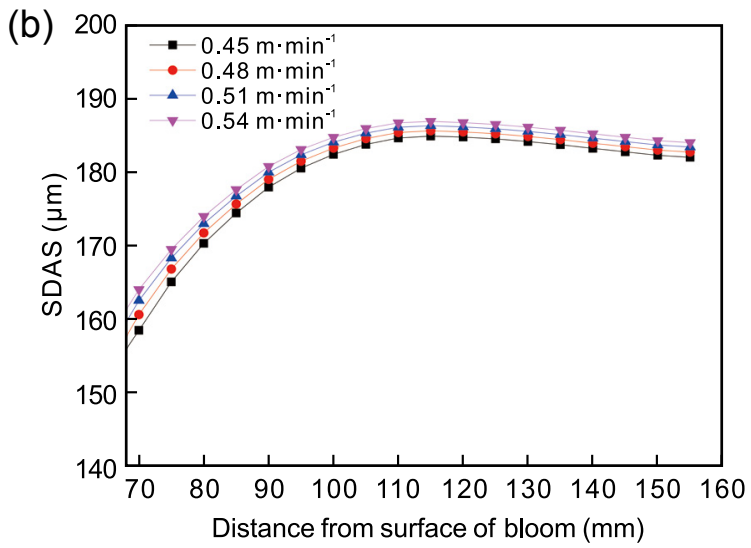

Fig. 9: SDAS at different positions from surface of bloom under different casting speeds

The simulated solidification structures under different casting speeds are shown in Fig. 10. It can be seen that when the casting speed is $0.45,0.48,0.51$, and $0.54 \mathrm{~m} \cdot \mathrm{min}^{-1}$, the ECR is $19.4 \%, 20.4 \%, 21.2 \%$ and $22.8 \%$, respectively. It indicates that the higher the casting speed, the greater the ECR. This is because the higher the casting speed, the lower the cooling intensity, resulting in a small temperature gradient at the solid-liquid interface, which inhibits the growth of columnar crystals.

As shown in Fig. 11, the average grain size gradually increases with the increase of casting speed. This is mainly due to the short residence time of the bloom in the strong cooling zone, especially in the mold, which is unfavorable for eliminating superheat of molten steel. Therefore, high casting speed can reduce the number of nuclei in molten steel.

\subsubsection{Effect of superheat}

With the casting speed of $0.54 \mathrm{~m} \cdot \mathrm{min}^{-1}$ and specific water flow of $0.16 \mathrm{~L} \cdot \mathrm{kg}^{-1}$, the solidification processes and solidification structures with superheat of 10, 20, 30 and $40 \mathrm{~K}$ were simulated.

The curves of SDAS at different positions under different superheat are shown in Fig. 12. It can be seen the superheat has little effect on the SDAS within $15 \mathrm{~mm}$ from the surface, which is mainly because the cooling intensity of the mold is high, and the superheat has little effect on the LST. In the range of 20-70 mm, the SDAS increases with the increase of superheat. In the range of $80-160 \mathrm{~mm}$, the SDAS decreases with the increase of superheat. When the degree of superheat increases from 10 to $40 \mathrm{~K}$, and the SDAS in the center of bloom decreases from 186.80 to $181.68 \mu \mathrm{m}$.

The reason why the SDAS in the $20-70 \mathrm{~mm}$ zone increases with the rise of superheat is that the high superheat makes the LST increase. However, in the 80-160 mm zone, the SDAS decreases with the increase of superheat. This is mainly because with the increase of superheat, the LST decreases in the $80-160 \mathrm{~mm}$ zone, as shown in Fig. 13, which makes the SDAS smaller.

With the increase of superheat from 10 to $40 \mathrm{~K}$, the ECR is about $40.5 \%, 22.8 \%, 16.7 \%$ and $14.6 \%$, respectively, as shown in Fig. 14. The reason may be that with the increase of superheat, the undercooling of the molten steel is difficult to meet the requirements of nucleation, which leads to the low nucleation rate of the molten steel. The formation of equiaxed crystals are inhibited by a low nucleation rate.

The average grain size increases with the rise of superheat, as shown in Fig. 15. However, when the superheat is higher than or equal to $30 \mathrm{~K}$, the change of grain size is no longer obvious, maybe because when the superheat increases to a certain extent, the increasing trend of temperature gradient becomes slower ${ }^{[21]}$ and the increasing amount of columnar crystal area becomes smaller. Higher superheat can greatly inhibit the nucleation and growth of equiaxed crystals. In addition, the higher the superheat, the more conducive to the growth of the columnar crystals. Therefore, a higher proportion of coarse columnar grains will increase the average grain size. 

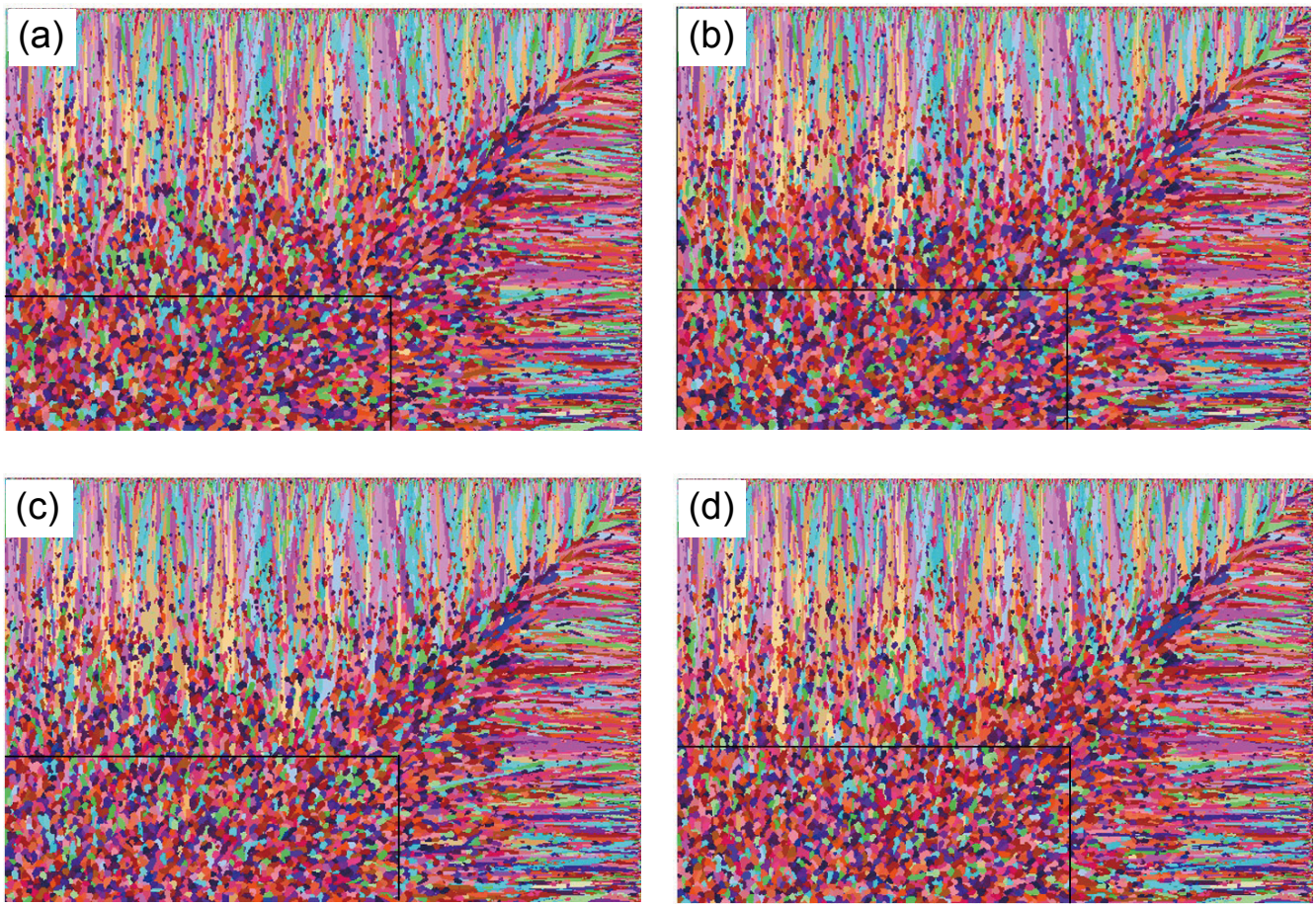

Fig. 10: Simulated solidification structures under different casting speeds: (a) $0.45 \mathrm{~m} \cdot \mathrm{min}^{-1}$; (b) $0.48 \mathrm{~m} \cdot \mathrm{min}^{-1}$; (c) $0.51 \mathrm{~m} \cdot \mathrm{min}^{-1}$; (d) $0.54 \mathrm{~m} \cdot \mathrm{min}^{-1}$

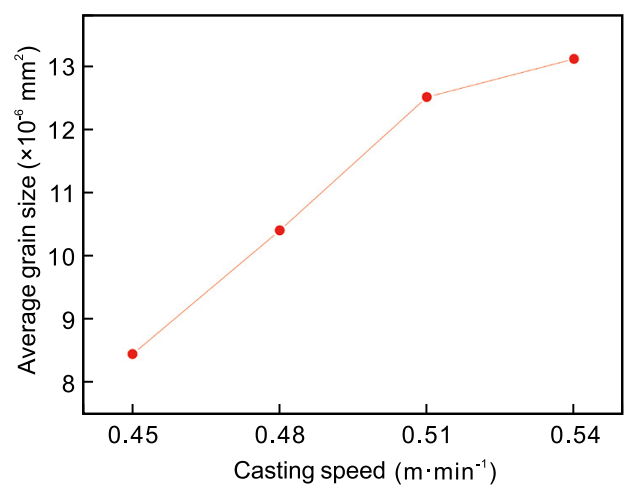

Fig. 11: Effect of casting speed on average grain size

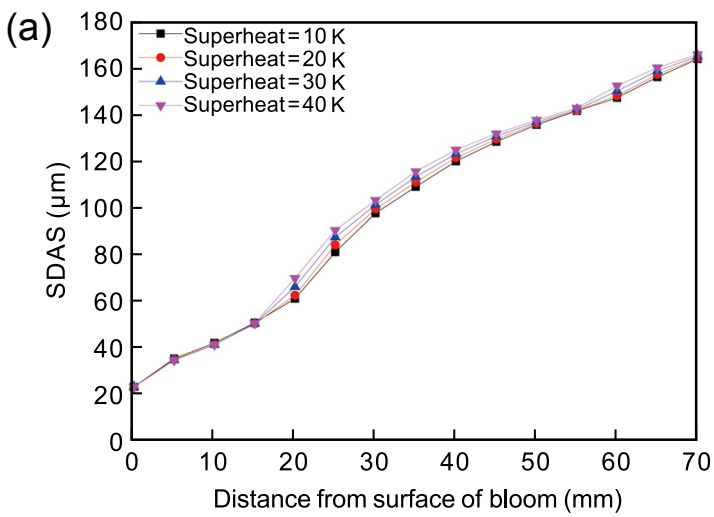

\subsubsection{Effect of specific water flow}

Under the condition of casting speed of $0.54 \mathrm{~m} \cdot \mathrm{min}^{-1}$ and superheat of $20 \mathrm{~K}$, the solidification processes were simulated for different specific water flows of $0.13,0.16,0.20$ and $0.23 \mathrm{~L} \cdot \mathrm{kg}^{-1}$, respectively. The heat transfer coefficients of secondary cooling zones with different specific water flows are shown in Table 6.

The curves of SDAS versus shell thickness under different specific water flows are shown in Fig. 16. It can be seen that as the specific water flow increases, the SDAS decreases. When the specific water flow increases from 0.13 to $0.23 \mathrm{~L} \cdot \mathrm{kg}^{-1}$, the SDAS at the center of the bloom is reduced from 185.87 to $182.48 \mu \mathrm{m}$.

(b)

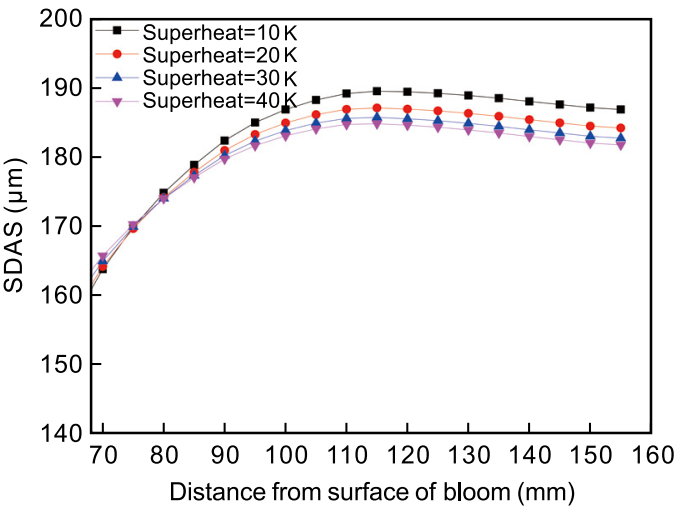

Fig. 12: SDAS at different positions from surface of bloom under different superheats

As the secondary cooling intensity is enhanced, the solidification rate of the bloom increases, which is beneficial to the formation of solidification structure with small dendrite spacing.

The simulated results of the solidification structure of the bloom under different specific water flows are shown in Fig. 17. With the increase of specific water flow, the ECR on the cross section of the bloom is about $23.3 \%, 22.8 \%, 19.8 \%$, and $18.75 \%$, respectively. It can be seen that as the specific water flow increases, the ECR decreases. The reason is that as the cooling intensity increases, the temperature gradient increases, which 


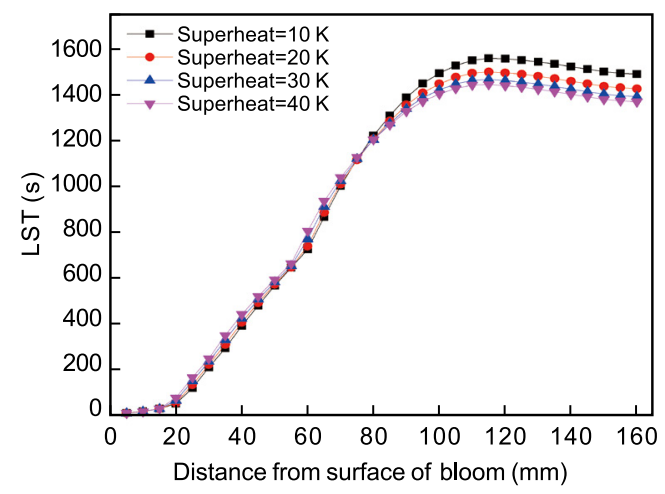

Fig. 13: LST at different positions from surface of bloom under different superheats
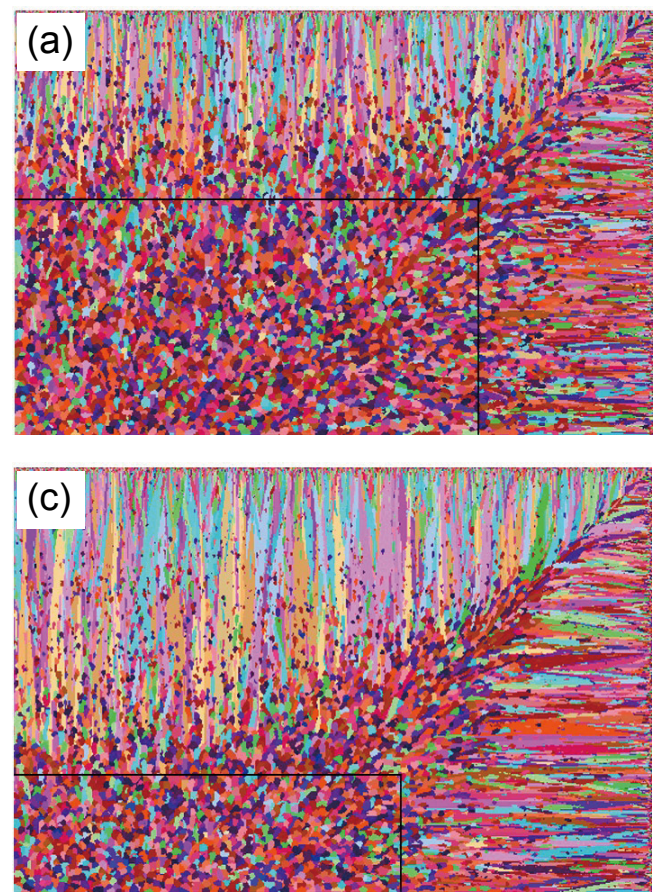

promotes the growth of columnar crystals.

The average grain size decreases at first and then increases with the increase of specific water flow, reaching the minimum value when the specific water flow is $0.20 \mathrm{~L} \cdot \mathrm{kg}^{-1}$, as shown in Fig. 18. With the increase of specific water flow, on the one hand, the formation of columnar crystals is promoted. On the other hand, columnar crystals and equiaxed crystals are refined, as shown in Fig. 16. However, when the specific water flow is greater than $0.20 \mathrm{~L} \cdot \mathrm{kg}^{-1}$, the average grain size increases, which is mainly because the increase of cooling strength makes the columnar crystal region further expand, and the refined equiaxed crystal is insufficient to offset the increase of grain size caused by the expansion of columnar crystal region.
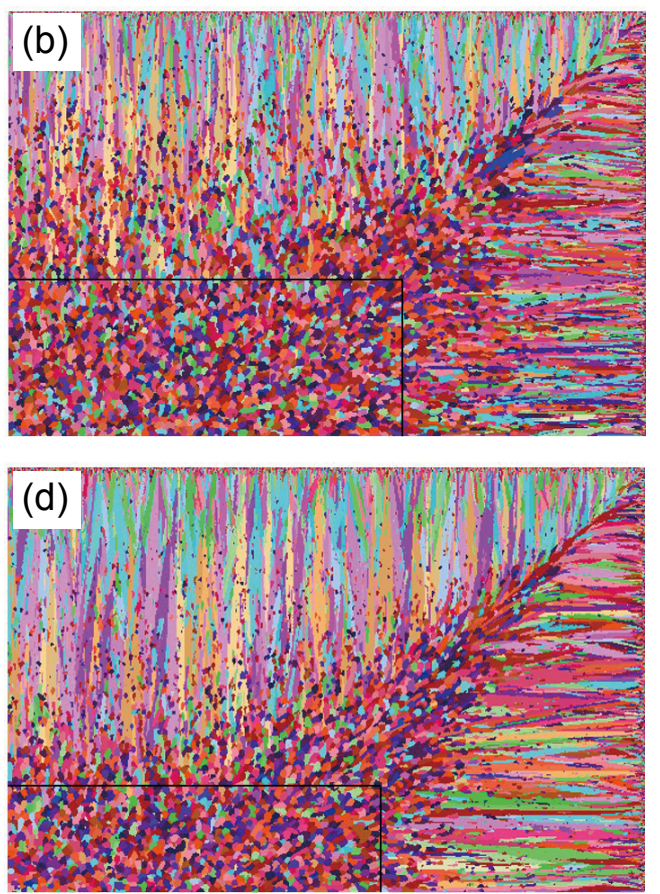

Fig. 14: Simulated solidification structures under different superheats: (a) $10 \mathrm{~K}$; (b) $20 \mathrm{~K}$; (c) $30 \mathrm{~K}$; (d) $40 \mathrm{~K}$

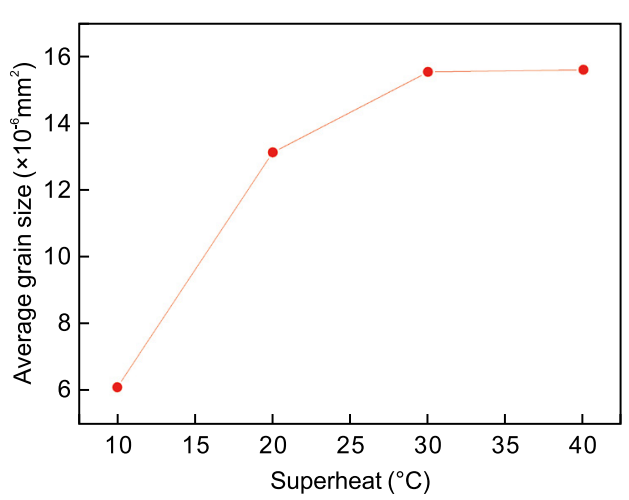

Fig. 15: Effect of superheat on average grain size

\subsection{Optimization of continuous casting process parameters}

Generally, the increase of ECR is beneficial for the elimination of center segregation. However, the increase of the ECR will increase the equiaxed crystal size of the central equiaxed crystal region ${ }^{[21,22]}$. That is to say, the expansion of the equiaxed region will increase the SDAS, thus increasing the permeability of the mushy region and increasing the trend of component segregation. ECR is not an absolute index of central segregation. Smaller grain size can improve the density of bloom, which is also one of the parameters to measure the central segregation.

According to the simulation results, higher superheat, stronger cooling and lower casting speed can reduce the SDAS in the equiaxed region. However, high superheat can also increase the SDAS in the columnar region and increase the trend of segregation. In addition, the average grain size increases with the rise of casting speed and superheat, but firstly decreases and then increases with the increase of specific water flow. When the specific water flow is $0.20 \mathrm{~L} \cdot \mathrm{kg}^{-1}$, the average grain size is the minimum. Therefore, the specific water flow was adjusted from 0.16 to $0.20 \mathrm{~L} \cdot \mathrm{kg}^{-1}$. The control range of superheat was increased from $10-20 \mathrm{~K}$ to $15-25 \mathrm{~K}$. Considering the rhythm of production, 
Table 6: Heat transfer coefficients of secondary cooling zones with different specific water flows

\begin{tabular}{cccccc}
\hline \multirow{2}{*}{ Specific water flow } & Boundary condition & \multicolumn{3}{c}{ Secondary cooling zone } \\
& Wide face & $h_{\mathrm{w}}=175$ & $h_{\mathrm{w}}=99$ & $h_{\mathrm{w}}=68$ & $h_{\mathrm{w}}=80$ \\
$0.13 \mathrm{~L} \cdot \mathrm{kg}^{-1}$ & Narrow face & $h_{\mathrm{w}}=176$ & $h_{\mathrm{w}}=98$ & $h_{\mathrm{w}}=68$ & $h_{\mathrm{w}}=78$ \\
& Wide face & $h_{\mathrm{w}}=191$ & $h_{\mathrm{w}}=110$ & $h_{\mathrm{w}}=70$ & $h_{\mathrm{w}}=85$ \\
$0.16 \mathrm{~L} \cdot \mathrm{kg}^{-1}$ & Narrow face & $h_{\mathrm{w}}=193$ & $h_{\mathrm{w}}=108$ & $h_{\mathrm{w}}=70$ & $h_{\mathrm{w}}=80$ \\
& Wide face & $h_{\mathrm{w}}=221$ & $h_{\mathrm{w}}=127$ & $h_{\mathrm{w}}=87$ & $h_{\mathrm{w}}=85$ \\
$0.20{\mathrm{~L} \cdot \mathrm{kg}^{-1}}^{*}$ & Narrow face & $h_{\mathrm{w}}=220$ & $h_{\mathrm{w}}=126$ & $h_{\mathrm{w}}=87$ & $h_{\mathrm{w}}=80$ \\
& Wide face & $h_{\mathrm{w}}=240$ & $h_{\mathrm{w}}=147$ & $h_{\mathrm{w}}=88$ & $h_{\mathrm{w}}=85$ \\
$0.23 \mathrm{~L} \cdot \mathrm{kg}^{-1}$ & Narrow face & $h_{\mathrm{w}}=240$ & $h_{\mathrm{w}}=147$ & $h_{\mathrm{w}}=88$ & $h_{\mathrm{w}}=80$
\end{tabular}

(a)

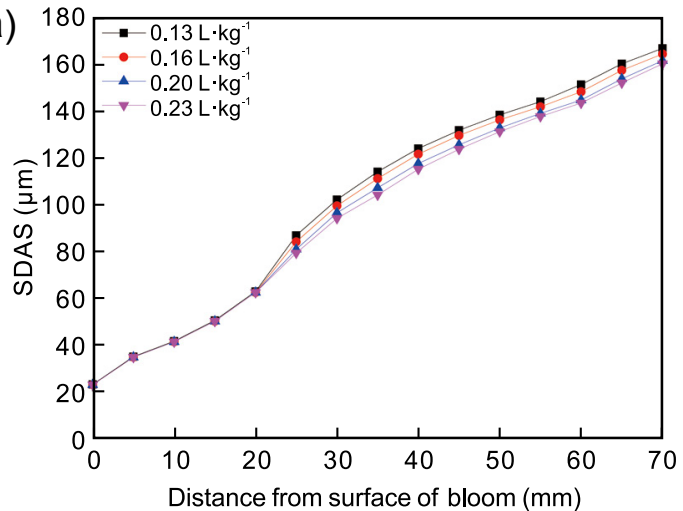

(b)

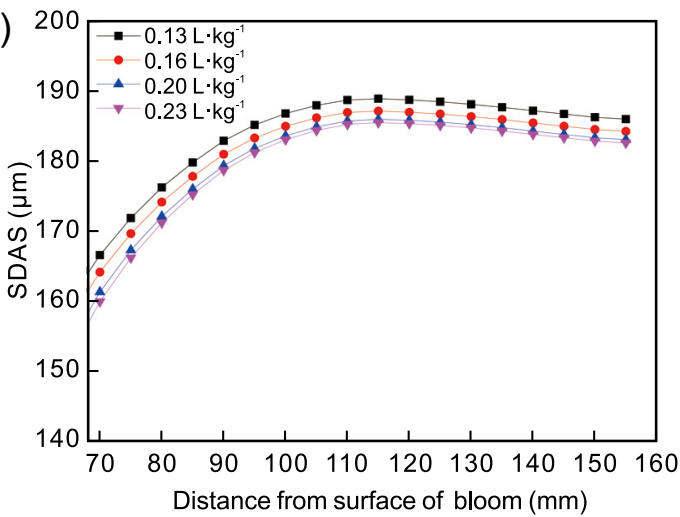

Fig. 16: SDAS at different positions from the surface of the bloom under different specific water flows
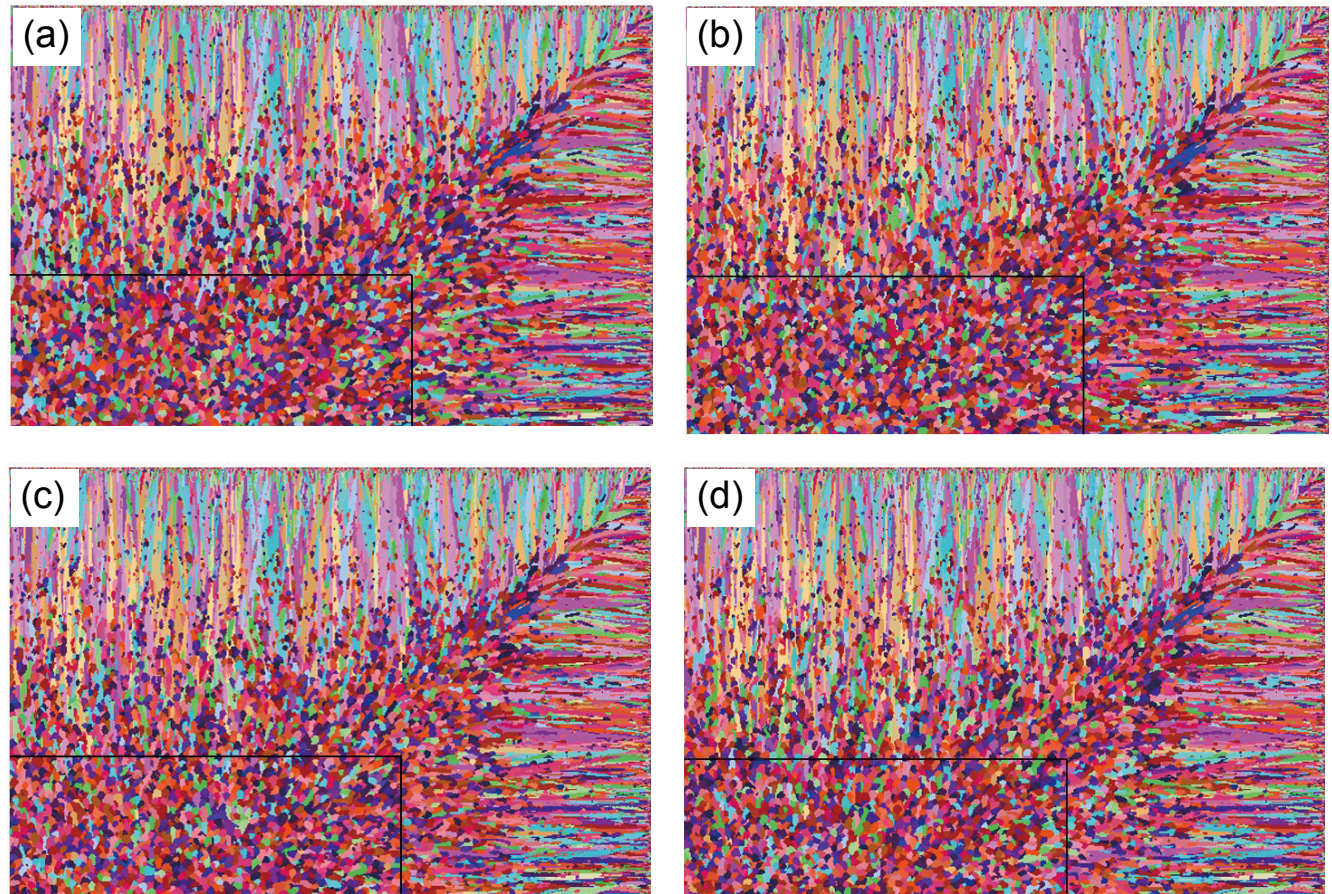

Fig. 17: Simulated solidification structures under different specific water flow: (a) $0.13 \mathrm{~L} \cdot \mathrm{kg}^{-1}$; (b) $0.16 \mathrm{~L} \cdot \mathrm{kg}^{-1}$; (c) $0.20 \mathrm{~L} \cdot \mathrm{kg}^{-1} ;$ (d) $0.23 \mathrm{~L} \cdot \mathrm{kg}^{-1}$ 


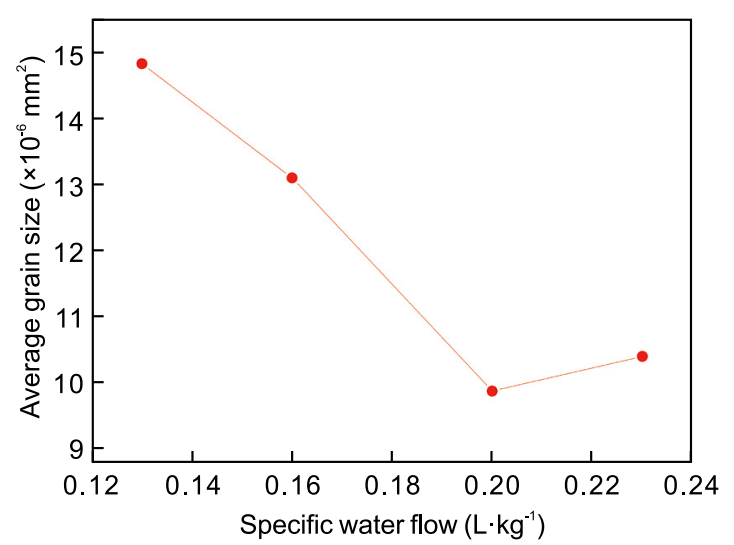

Fig. 18: Effect of specific water flow on average grain size

the casting speed was adjusted from 0.54 to $0.51 \mathrm{~m} \cdot \mathrm{min}^{-1}$.

Therefore, the continuous casting process parameters were optimized, and the industrial test was carried out according to Table 7.

Table 7: Process parameters before and after optimization

$\begin{array}{cccc} & \begin{array}{c}\text { Casting speed } \\ \left(\mathrm{m}^{\mathrm{min}} \mathrm{m}^{-1}\right)\end{array} & \begin{array}{c}\text { Specific water flow } \\ \left(\mathrm{L} \cdot \mathrm{kg}^{-1}\right)\end{array} & \begin{array}{c}\text { Superheat } \\ (\mathrm{K})\end{array} \\ \begin{array}{c}\text { Before } \\ \text { optimization }\end{array} & 0.54 & 0.16 & 18 \\ \begin{array}{c}\text { After } \\ \text { optimization }\end{array} & 0.51 & 0.20 & 23\end{array}$

The blooms were drilled and chipped as shown in Fig. 19. Carbon-sulfur analyzer was used to obtain the carbon content at different locations in the blooms. The carbon segregation index, $C_{\text {index }}$, can be calculated by Eq. (20):

$$
C_{\text {index }}=\frac{C}{C_{0}}
$$

where $C$ is the carbon content of drillings, and $C_{0}$ is the carbon content of liquid steel in the tundish.

The carbon segregation index before and after optimization was obtained which is shown in Fig. 20. It can be seen that the carbon segregation at the center of the bloom is reduced from 1.11 to 1.075 . It proves that the central segregation of the bloom can be improved by decreasing the SDAS and average grain size.

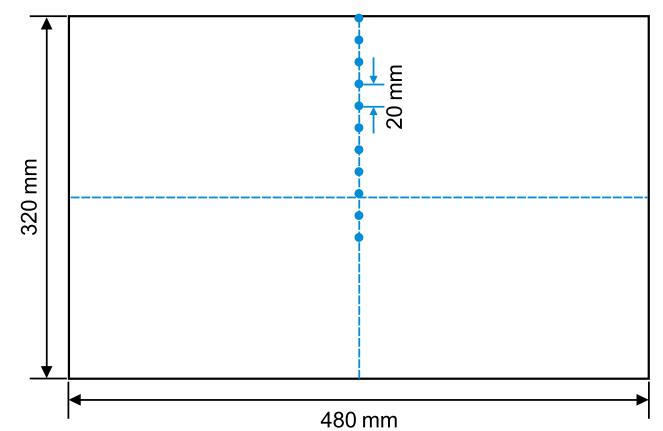

Fig. 19: Carbon segregation sampling schematic

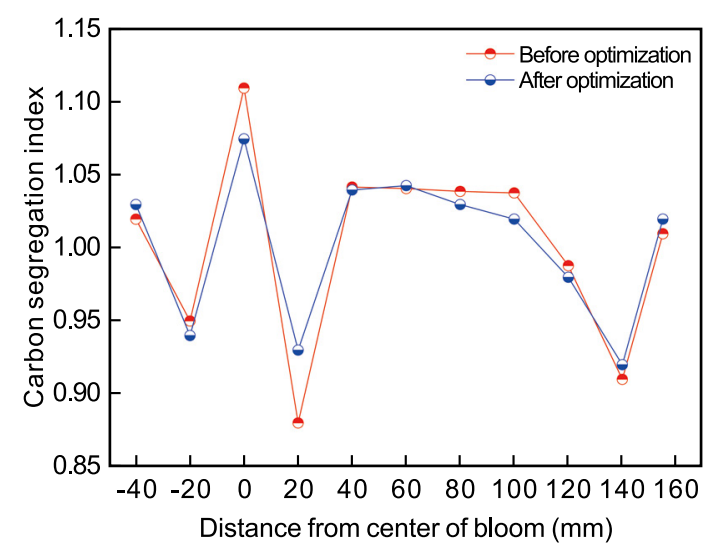

Fig. 20: Comparison of carbon segregation index before and after optimization

\section{Conclusions}

(1) The SDAS model for GCr15 bloom was obtained. When the cooling rate is lower than $20 \mathrm{~K} \cdot \mathrm{min}^{-1}$, the calculated value of the model is in good agreement with the measured value. The decrease of the casting speed and the increase of the specific water flow both are beneficial for the reduction of the SDAS. The influence of superheat on the SDAS is complex, and it reduces the SDAS in the central equiaxed region.

(2) The ECR increases with the rise of casting speed and decreases with the rise of specific water flow. The superheat has a great influence on the ECR, which is mainly because the increase of superheat greatly reduces the nucleation quantity in the molten steel.

(3) The average grain size increases with the rise of the casting speed and superheat. It decreases at first and then increases with the increase of specific water flow. When the specific water flow is $0.20 \mathrm{~L} \cdot \mathrm{kg}^{-1}$, the average grain size reaches the minimum.

(4) With the optimized process parameters, the central carbon segregation index is reduced from 1.11 to 1.075. This is mainly due to the decrease of the SDAS in the equiaxed region, which increases the density and improves the central carbon segregation.

\section{Acknowledgements}

This research was financially supported by the National Natural Science Foundation of China (Grant Nos. 51774030 and U1860104) and the Fundamental Research Funds for the Central Universities (FRF-TP-20-029A1).

\section{References}

[1] Dong Q P, Zhang J M, Liang Q, et al. Numerical modeling of macrosegregation in round billet with different microsegregation models. ISIJ Int., 2017, 57(5): 814-823.

[2] Zeng J, Chen $W$ Q, Wang $Q X$, et al. Improving inner quality in continuous casting redangular billets: Comparison between mechanical soft reduction and final electromagnetic stirring Trans. Indian Inst. Met., 2016, 69(8): 1623-1632. 
[3] Bleck W, Wang W, Bülte R. Influence of soft reduction on internal quality of high carbon steel billets. Steel Res. Int., 2006, 77(7): 485-491.

[4] Li Y J, Li L, Zhang J Q. Study and application of a simplified soft reduction amount model for improved internal quality of continuous casting bloom. Steel Res. Int., 2017, 88(12): 170-176.

[5] Jiang D B, Zhu M Y. The fluid flow and solidification phenomenon in billet continuous casting process with mold and final electromagnetic stirrings. Nastac L et al. (eds), Advances in the Science and Engineering of Casting Solidification, Springer, Cham. doi.org/10.1007/978-3-319-48117-3_11.

[6] Cicutti C, Boeri R. On the relationship between primary and secondary dendrite arm spacing in continuous casting products. Scr. Mater., 2001, 45: 1455-1460.

[7] El-Bealy M, Thomas B G. Prediction of dendrite arm spacing for low alloy steel casting processes. Metall. Mater. Trans. B, 1996, 27(4): 689-693.

[8] An H H, Bao Y P, Wang M, et al. Numerical and experimental investigation of solidification structure evolution and reduction of centre segregation in continuously cast GCr15 bloom. Ironmaking Steelmaking, 2019: doi.org/10.1080/03019233.201 9.1672447.

[9] Savage J, Pritchard $\mathrm{W} \mathrm{H}$. The problem of rupture of the billet in the continuous casting of steel. J. Iron Steel Inst., London, 1954, 178(3): 269-277.

[10] Ha J S, Cho J R, Lee B Y, et al. Numerical analysis of secondary cooling and bulging in the continuous casting of slabs. J. Mater. Process. Technol., 2001, 113: 257-261.

[11] Hardin R A, Liu K, Beckermann C, et al. A transient simulation and dynamic spray cooling control model for continuous steel casting. Metall. Mater. Trans. B, 2003, 34(3): 297-306.

[12] Nozaki T, Matsuno J I, Murata K, et al. A secondary cooling pattern for preventing surface cracks of continuous casting slab. Trans. Iron Steel Inst. Jpn., 1978, 18(6): 330-338.
[13] Rappaz M, Gandin C A. Probabilistic modelling of microstructure formation in solidification processes. Acta Metall. Mater., 1993, 41: $345-360$

[14] Gandin C A, Rappaz M. A coupled finite element-cellular automaton model for the prediction of dendritic grain structure in solidification processes. Acta Metall. Mater., 1994, 42(7): 2233-2246.

[15] Kurz W, Giovanola B, Trivedi R. Theory of microstructural development during rapid solidification. Acta Metall., 1986, 34: 823-830.

[16] Gan Y, Ni M, Yu Z X, et al. Practical manual of modern continuous cast steel. Beijing: Metallurgical Industry Press, 2010: 52-53. (In Chinese)

[17] Chen J X. Chart data manual for steelmaking. Beijing: Metallurgical Industry Press, 2004: 579-580. (In Chinese)

[18] Li W C. Metallurgy and physical chemistry of materials. Beijing: Metallurgical Industry Press, 2001: 531-533. (In Chinese)

[19] Fang Q, Ni H W, Zhang H, et al. Numerical study on solidification behavior and structure of continuously cast U71Mn steel. Metals, 2017, 7(11): 1-13.

[20] Pequet C, Rappaz M, Gremaud M. Modeling of microporosity, macroporosity, and pipe-shrinkage formation during the solidification of alloys using a mushy-zone refinement method: applications to aluminum alloys. Metall. Mater. Trans. A, 2002, 33: 2095-2106.

[21] Hou Z B, Cheng G G, Jiang F, et al. Compactness degree of longitudinal section of outer columnar grain zone in continuous casting billet using cellular automaton-finite element method. ISIJ Int., 2013, 53(4): 655-664.

[22] Hou Z B, Jiang F, Cheng G G. Solidification structure and compactness degree of central equiaxed grain zone in continuous casting billet using cellular automaton-finite element method. ISIJ Int., 2012, 52(7): 1301-1309. 